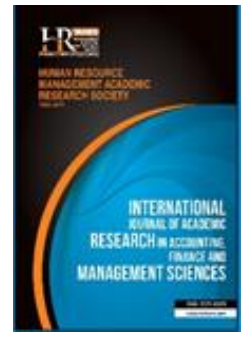

International Journal of Academic Research in Accounting, Finance and Management Sciences

Vol. 10, No.2, April 2020, pp. 111-121

E-ISSN: 2225-8329, P-ISSN: 2308-0337

(c) 2020 HRMARS

www.hrmars.com

To cite this article: Anghelache, C., Armeanu, D. S. (2020). The Portfolio Decisions for Assets with Varying Returns over Time and Labor Income, International Journal of Academic Research in Accounting, Finance and Management Sciences 10 (2):111-121.

\title{
The Portfolio Decisions for Assets with Varying Returns over Time and Labor Income
}

\author{
Constantin Anghelache ${ }^{1}$, Daniel Stefan Armeanu ${ }^{2}$ \\ ${ }^{1}$ Bucharest University of Economic Studies, Artifex"University of Bucharest, ${ }^{1}$ E-mail: actincon@yahoo.com \\ ${ }^{2}$ Bucharest University of Economic Studies, ${ }^{2}$ E-mail: darmeanu@yahoo.com
}

\begin{abstract}
We will try to expand the analysis of assets including labor income in the decisions regarding the accumulation of assets and their allocation. This refers to pension funds and retirement income. Many issues arise in this context. We need to clarify whether future obligations can be covered by contributions from labor income and assets; what fraction of the income must be saved in order to obtain sufficient retirement income; there will be sufficient income and income from pensions at the complete retirement stage; to what extent retirement funds should be engaged in risky assets or which are the relevant factors that determine the upward or downward evolution of assets and the dispersion of capital. The issues mentioned are of a complex political and financial nature. As regards pension and pension funds, in many countries, the tendency is to establish a three-pillar system for pension income: first, a social security system, secondly, a pension fund. related to work and thirdly, a private pension fund. For most of these pillars, saving on labor income, in addition to capital income, has become an important element. Both help reduce the risk and increase the pension income. As we will see, income from work is also important for the problem of wealth growth. This aspect suggests several directions regarding the design of pension funds, as well as the saving and portfolio decisions regarding labor income. Portfolio studies that include labor income are rare. It was emphasized that financial theory should not be used primarily to "hit the market" but to contribute to raising the capital of households. Fund management should be primarily a dynamic diversification, provide provisions against adverse shocks and ensure the accumulation of sufficient wealth for future periods. Traditional mutual funds, as well as insurance schemes and publicly supported pension funds are management tools that address these issues. However, one also needs well-regulated financial institutions to help serve what the financial theory has actually proposed: serving individuals and households with assets and labor income to provide sufficient pension and temperance funding. adverse shocks.
\end{abstract}

Key words

Yield, Income, Pension Funds, Assets, Capital, Risk, Frequency, Dynamic Programming.

\begin{tabular}{|c|c|c|}
\hline Received: & 20 May 2020 & (c) The Authors 2020 \\
\hline Revised: & 10 Jun 2020 & Published by Human Resource Management Academic Research Society (www.hrmars.com) \\
\hline $\begin{array}{l}\text { Accepted: } \\
\text { hed Online: }\end{array}$ & $\begin{array}{l}15 \text { Jun } 2020 \\
20 \text { Jul } 2020\end{array}$ & $\begin{array}{l}\text { This article is published under the Creative Commons Attribution (CC BY 4.0) license. Anyone may } \\
\text { reproduce, distribute, translate and create derivative works of this article (for both commercial and } \\
\text { non-commercial purposes), subject to full attribution to the original publication and authors. The full } \\
\text { terms of this license may be seen at: http://creativecommons.org/licences/by/4.0/legalcode }\end{array}$ \\
\hline
\end{tabular}

\section{Introduction}

A dynamic portfolio approach should also include labor income in the dynamic decision-making process of accumulating and allocating assets and how long it is unclear whether asset risk prices and their returns evolve according to the business cycle, one of the most cited stylized facts. it is the fact that the income of the labor force evolves strongly with the business cycle. The problem of saving income, creating buffer stocks against adverse shocks or securing pension income, can be tackled through the organizational form of a private insurance system, a public pension fund, as in many European countries, the employersponsored pension fund. or other mixed pension possibilities. Many systems currently operating, ranging 
from publicly managed funds - paid systems and up to private pension fund systems, have insufficient coverage of the future prospects of the funds. Public pension funds do not work well to ensure sufficient and persistent risk-free income. In many countries, changing the macroeconomic environment has led to changes in pension incomes even for publicly funded pension fund systems. Many countries target pension variants through the aforementioned three-pillar system: the public pension system to guarantee a subsistence income, workplace pension funds (with significant company contribution) and additional private pension funds.

In many states, proposals for the creation of guaranteed pension accounts discussing tax exemptions or subsidies for savings in the necessary, guaranteed pension funds, discussing tax exemptions or subsidies for savings in the required pension funds are discussed. Certain returns of pension funds are guaranteed and a certain percentage of the income is insured after retirement. We will consider a decision model regarding the accumulation of assets and portfolio if there are profits from the accumulated financial funds, as well as from the income from the workforce, as mentioned above. We do not refer to the specific institutional arrangement of such a model, but rather we want to contribute to understanding how the interaction between income from labor and income from labor could work to create stable and sufficient funds. All the variants face the problem how much should be consumed from the current income, how much to save and how to optimally diversify the economies and allocate them to the different assets. All variants face the problem of dynamic economies and portfolio decisions. When we want to include, besides the income from the assets, the income from the labor force in the dynamics for capital, we must emphasize that, in fact, it adds a different risk. The risk of income from work mainly results from the risk of work, which usually has cyclical characteristics. This background risk is compared to the underlying risk that affects the income for risky assets, such as dividends from equity or bond income. A more general approach should take into account age and income from human capital in an equity equation. We refer here to only one type of income from work. In the context of the modeling approach, an important component of the inputs will be the labor income. In terms of return on assets, we will try to distinguish between the real income of the labor force and the low frequency component of the labor income. Generally, the models of accumulation of assets with the labor income usually face the problem that there are heterogeneous agents not only in terms of age and human capital, but also in terms of risk taking and time horizon. There are households with different levels of wealth and different savings rates. To take these issues into consideration, many researchers have worked with a two-period model: one for active working time and another for retirement.

This could lead to a life cycle model. This aspect may require analysis for different time horizons: the period of time with high incomes from work and the period with high incomes from pensions. To solve this aspect of the time horizon, we will use a model with different reduction rates for different time horizons.

We will estimate the low frequency components for labor income by using spectral analysis in our dynamic decision model.

This approach can be viewed as an aggregate model for labor income over time. Although the model can be used for individual investors, we mainly refer to aggregate savings and portfolio decisions. If we had adequate data for individual investors, we could follow with this method, an individual decision model, for example a life cycle model. We will depart from the assumptions that the consumption-capital ratio and the estimated capital premium are constant, they are variable over time. We will start from the hypothesis of an interest without constant risk and make it time dependent. We will use an estimated time series of labor income in the business cycle. In other words, we use the low frequency movement of labor income obtained through some estimates of time series data.

\section{Literature review}

Anghelache (2008) used the statistical indicators in economic-financial analyzes. Bewerunge \& Rosen (2013) analyzed the correlation between wage differences, pensions and compensation in the publicprivate sector for older employees. Campbell \& Viceira (2002) studied thevportfolio selection models for long-term investors. A similar theme is treated by Liu (2007), which refers to stochastic environments, as well as by Wachter (2002). Chetty addressed issues related to the statistical methods used in welfare analysis. Corbore et al. (2006) presented the main theoretical and practical notions of econometrics. Hsiao 
\& Semmler (2009) analyzed a number of elements regarding long-term financial data. Kumho et al. (2015) have tried to identify levers that can be used in crisis management. Markowitz (2010) presented the arguments of modern portfolio theory. Milanovic (2010) studied the methods of measuring inequality existing worldwide. Newbold et al. (2010) outlined the main concepts used in business statistics. Piketty (2014) analyzed aspects regarding the distribution of assets and the dynamics of capital accumulation. Van Rooij et al.(2007) studied the relationship between profitability and existing risk in the field of pensions: Wolff (2013) investigated the correlation between asset prices and wealth of the middle class. Yin (2009) proposed an econometric model estimating the scale of the underground economy.

\section{Methodology of research, data, results and discussions}

\subsection{The evolution of analyzes on the asset market}

We suppose that the investor in the asset market receives, in addition to income from the asset markets, income from the labor force. A common approach is to assume that the income of the labor force is distributed in a lognormal way, presenting a constant growth rate and a random shock. Basically, the growth rate of labor income $L_{t+1}$ can be summarized in the relation:

$$
\Delta l_{t+1}=\log L_{t+1}-\log L_{t}=g+\varepsilon_{t+1}
$$

Then, we will assume a risky asset and a risk-free asset as investment devices. Given the function of the investor's capital with CRRA preferences and the relative risk aversion coefficient $\gamma$, we can summarize the commonly used model with a horizontal zero.

We will consider: $\max E_{t}\left[\rho \frac{c_{t+1}^{1-\gamma}}{1-\gamma}\right]$

$$
C_{t+1}=W_{t}\left(1+R_{p, t+1}\right)+L_{t+1}
$$

$$
\text { Where } R_{p, t+1}=\alpha_{t}\left(R_{t+1}-R_{f}\right)+R_{f}
$$

Here is the fraction of the funds allocated to the risky asset, the yield from the risky asset $R_{t}$, the interest rate without risk (assumed to be a constant) $R_{f}$ and the average portfolio returns $R_{p, t+1}$. We assume labor income as well as income from assets that can be used to accumulate assets in the future. The solution of the above model and the change of the risk assumed when the income from work is included in the equation of wealth, is widely approached by many researchers. The usual result, in the context of a simple model of a period, is that, because wage income can be regarded as an income from assets (for human capital), it can, in a way, covariate with income from equity (as a fraction of the portfolio total). Then, to the extent that the variation in stock returns is offset by the investor's salary income, the shares actually become less risky, and the investor with salary income may therefore have more risky stocks. In other words, a negative co-variation in equities and wages may cause the investor to hold riskier stocks. This proposal depends, of course, on the exact empirical relation of the statistical convergence of the flow of wage incomes and on the return on equity.

We will observe a multi-period, in fact, a model of infinite time horizon of allocation of assets with labor income. We will choose a synthetic approach and play an infinite horizon model with high reduction rates as an approximation for a finite time horizon model. As mentioned, we use the resemblance of a model with a discrete time structure (finite time) and a continuous time, infinite horizon model that works as follows. To begin with, we postulate that there are two periods for someone, the period in which he is involved in the active working life, as well as the possibility of retiring: the employment stage and the retirement stage. In the first period there is a positive probability of employment $\pi^{B}=1-\pi^{r}$, whereby $\pi^{r}$ is the probability of retirement. The pension can be defined as a stage in which there is no income from work. Thus, in the context of the current model, if retirement occurs, the income from work is zero. However, if a secrecy happens, there is a positive probability that the investor will disappear. This positive 
probability is postulated to be $\pi^{d}$ so that the expected life time after retirement is $1 /^{\pi^{d}}$. Using this reasoning we can capture the horizons of investors in an infinite horizon model. Suppose that the agencies do not optimize the contribution of the workforce as in the typical Real Business Cycle model and we seek rather to improve the welfare compared to the consumption flows.

$$
\begin{aligned}
& \text { We consider:: } \max E_{t}\left[\sum_{t=0}^{\infty} \rho^{t} \frac{c_{t+1}^{1-\gamma}}{1-\gamma}\right] \\
& W_{t+1}=\left(W_{t}+L_{t}-C_{t}\right)\left(1+R_{p, t+1}\right) \\
& \text { Where } R_{p, t+1}=\alpha_{t}\left(R_{t+1}-R_{f}\right)+R_{f}
\end{aligned}
$$

When the wealth increases with a ${ }^{\alpha_{t}}$, if the return on risky assets is higher than the risk-free asset and the wealth increases with a lower consumption, then a better saving results. The details of such a study on how the two decision variables ${ }^{\alpha_{t}}$ and $C_{t}$ affect the accumulation of assets are undertaken in Semmler et al. (2009). For the energy utility mentioned above, as preferences over consumption, two Euler equations can be obtained in which different reduction rates are involved, depending on the two hypotheses in which the investor is in the period in which it is still operating or withdrawing. For the period when the investor is retired, the Euler relationship must be confirmed:

$$
1=E_{t}\left[\left(1-\pi^{d}\right) \rho\left(\frac{C_{t+1}^{r}}{C_{t}^{s}}\right)^{-\gamma}\right]\left(1+R_{p, t+1}\right)
$$

For the period during which the investor also has income from work accumulating assets for retirement, he will hold:

$$
1=E_{t}\left\{\left[\pi^{e} \rho\left(\frac{C_{t+1}^{e}}{C_{t}^{e}}\right)^{-\gamma}+\left(1-\pi^{e}\right)\left(1-\pi^{d}\right) \rho\left(\frac{C_{t+1}^{r}}{C_{t}^{e}}\right)^{-\gamma}\right]\left(1+R_{p, t+1}\right)\right\}
$$

In this case, the capital $e$ refers to the status of employee and $r$ to the retired status of the investor and we can identify $R_{p, t+1}$ as the return of the investor's portfolio. Then the investor considers the probability of the two possible statutes for the following period: either the agent is employed (the probability $\pi^{e}$ ) or is retired and still lives (the probability $\left(1-\pi^{e}\right)\left(1-\pi^{d}\right)$. On the right side of the last equation is the expected utility gain from an investor, the left side of the last equation. Then those equations and the corresponding budget constraint are linearized and result from this expression for approximately log consumption for the retirement period:

$$
c_{t}^{r}=b_{0}^{r}+b_{1}^{r} w_{t}
$$

An employed agent holds the approximate amount, according to the relationship:

$$
c_{t}^{e}=b_{0}^{e}+b_{1}^{e} w_{t}+\left(1-b_{1}^{e}\right) l_{t}
$$

In the above equations, $b_{0}^{i}$ and $b_{1}^{i}$ re constant and $w_{t}=\log W_{t}$ and $l_{t}=\log L_{t}$. From these linearizations, some obtain the approximate fractions $\alpha^{r}$ and $\alpha^{e}$ and the fractions invested in risky assets, in the retirement period and the employed period. As a result of the configuration of the model, both the consumption capital ratios and the fraction of wealth allocated to risky assets are constant. The major results are: first, as the agents approach retirement ( ${ }^{\pi^{e}}$ is lower), the fraction of the agent's invested assets in risky assets decreases sharply. This also depends on the risk aversion $y$ parameter. Second, if income from work is risk-free, it increases the fraction held in risky assets, such as equity. The latter result is due to the risk-free income, the flow of income from the labor force, which contributes to the total risk-free income and thus inclines the portfolio towards a higher share of the financial assets from risky assets. We note that these results could be modified in the context of the nonlinear solution procedure. 


\subsection{Business cycles, asset returns and labor income}

The procedure allows us not only to move away from the simplified assumption of previous literature, but also to use real time series data on labor yields and incomes, the evolution of the macroeconomics defined by GDP, consumption, investments, net imports, employment. labor, labor force and income from assets providing important information for saving and asset allocation. Asset managers not only pursue technical portfolio allocation models, but also observe and monitor the macroeconomic environment when rebalancing portfolios. This is why we need to include specific references to the empirical business cycle literature. We summarize some data from the business cycle regarding the returns on assets and labor and labor income.

Regarding the financial market, this considers a stylized fact that the cash flows of companies are very volatile, but usually pro-cyclical. Also, nominal interest rates are pro-cyclical. The risk premium for bonds with different maturities increases with the maturity of the bonds (upward sloping yield curve, due to high interest rates) and decreases at the beginning of the recession (lower interest rates). The risk premium for private bonds (private debt) and the difference between corporate invoices and Treasury yields (with a maturity of 6 months) tend to decrease during expansions and increase during recessions. This reflects the risk of non-payment on time. Stock prices and yields tend to present a risk premium that exceeds bond yields, but volatility is higher. Although, in general, stock prices are positively related to longterm GDP growth rates, the volatility of stock prices makes the tight relationship rather unclear in the short term. Often, stock prices anticipate the growth rate of output, but the impact of other variables on the volatility of the financial market often tries to link the relationship between the stock price and output growth. Thus, risky returns on stock markets rarely indicate a clear correlation with a certain measure of the business cycle.

On the other hand, labor market variables are more clearly correlated with a certain measure of business cycles, for example production. Capacity utilization is strongly correlated with the business cycle, as well as employment and capacity utilization.

The employment coincides with the fluctuation of production, but is less volatile than production. Most of the changes in the total jobs correspond to the average weekly hours worked, but with the activity of the labor force in and out of the workplace. Although real wages are usually only slightly pro-cyclical, the total income of the labor force, as used in this study, is significantly pro-cyclical. This results from work in and out of work. We believe that the latter should be the appropriate measure for the income of the labor force in the context of an asset accumulation model. Data sources and estimation of low-frequency components of risky returns and risk-free returns are reported in Hsiao and Semmler (2009). Aici raportăm coeficienții estimate. As previously demonstrated, the average short-term interest rate profits, $R_{f, t}$ and randamentul capitalului $R_{e_{2} t}$, return on capital, are time-dependent and can be formulated after the relationship:

$$
R_{f, t}=-0,0021(t)+0,0521+\sum_{i=1}^{2}\left(a_{i} \sin \left(\frac{2 \pi}{\tau_{i}}(t)\right)+b_{i} \cos \left(\frac{2 \pi}{\tau_{i}}(t)\right)\right)
$$

with ${ }^{\tau_{\tilde{i}}}$ and the coefficients $a_{\bar{i}}, b_{i}$ are given.

Also taking the first two estimated components of equity returns the evolution of low frequency returns can be:

$$
R_{e_{i}, t}=-0,0046(t)+0,1259+\sum_{i=1}^{2}\left(a_{i} \sin \left(\frac{2 \pi}{\tau_{i}}(t)\right)+b_{i} \cos \left(\frac{2 \pi}{\tau_{i}}(t)\right)\right)
$$

For the empirical estimation of the low frequency components of labor income we use monthly data. The nominal series has been transformed into real labor income by using the CPI. The extent to which the inclusion of labor income in a portfolio and the pattern of accumulation of assets could be relevant is indicated by the weight of the incomes obtained in the total income. The share of labor income in total income is about $70 \%$, while the share of income from share capital (interest, dividends and rents) is about $30 \%$, all before taxation. We used the procedure for estimating the low frequency components of labor 
income. The estimation of the periods of 25 and 8 years is sufficient and significant. The result of the coefficient estimates is as follows:

$L_{t}=92,8(t)+1402,3+\sum_{i=1}^{2}\left(a_{i} \sin \left(\frac{2 \pi}{\tau_{i}}(t)\right)+b_{i} \cos \left(\frac{2 \pi}{\tau_{i}}(t)\right)\right)$

Table 1. The estimates of the coefficients for the low frequency components of labor income

\begin{tabular}{|c|c|c|c|c|c|}
\hline$a_{1}$ & $a_{2}$ & $b_{1}$ & $b_{2}$ & $\tau_{1}$ & $\tau_{2}$ \\
\hline 16,244 & 2,911 & 101,879 & 41,692 & 305,00 & 101,67 \\
\hline
\end{tabular}

By this the first two terms represent the tendency component of the labor income, and the rest of the components are cyclical.

\subsection{Dynamic decisions in the accumulation of assets}

If the probability of being hired is zero, only the second part of the Euler equation tends to hold. We are considering the incomes of the labor force and we could treat investors approaching retirement as characterized by a shorter expected life time and we use $1 / \pi^{\pi^{d}}$ as expected life time. However, the larger it is, the term $\left(1-\pi^{d}\right)$ is the smaller and thus the reduction factor $\left(1-\pi^{d}\right) \rho$ will be lower and the rate of reduction will be higher. Since the capital is affected by the labor income, we can treat the investor by analyzing both the labor income and the retirement income and study the effect of the investor's time horizon by modifying the actual updating factor $\left(1-\pi^{d}\right) \rho$. If $\pi^{d}$ tends to zero, the usual discount rate is addressed. Next, we will use the dynamic programming procedure to explore the effects of the investor's time horizon on consumer decisions, asset allocation, on the fate of the investor's wealth and well-being. In studying this situation, we use low frequency movements for equity and short term bond returns. We will provide the variety of discount rates to study the effect of the different time horizon on investors. We again allow for expected returns of various times, given by the evolutions of low frequency estimated returns. We also estimate variable labor incomes over time.

The risk aversion parameter is considered $\gamma=0,8$ because this case gives us increasing capital. We will consider that long-term investors, with a long term to retire, would have a small discount rate. As in the previous models, we assume that the investor would respond to the new investment opportunities given by the time path of interest rate (risk-free), capital return and labor income.

We will also explore the effect of the change in the rate of reduction on consumption ${ }^{C}$, the weight for the choice of equity, an "accumulation" and the fate of the capital and the welfare of the investor. In the analysis we use a portfolio of two assets, equity and short-term bonds. The yield given by the shortterm interest rate and the condition that there is an exogenous income stream of the labor force. We will allow for various expected time variations given by low frequency evolutions, using estimates. The result of $\mathrm{PD}$ is given by the relation:

$$
\begin{aligned}
& \max _{\{C, \alpha\}} \int_{0}^{\infty} e^{-\delta t} U\left(C_{t}\right) d t \\
& \dot{W}(t)=\alpha_{t} R_{e_{t} t} W_{t}+\left(1-\alpha_{t}\right) R_{f, t} W_{t}+L_{t}-C_{t} \\
& \dot{x}(t)=1
\end{aligned}
$$

With ${ }^{R_{e, t}}, R_{f, t}$ and ${ }^{L_{t}}$ following a harmonic oscillation defined above. In the PD problem, as formulated, we replaced the $C_{t}$, control, with the $c_{t}=\frac{c_{t}}{W_{t}}$ control, with $0<c_{t}<1$ and $C_{t}=c_{t} W_{t}$. We have introduced in the PD algorithm, the time index $\dot{x}(t)=1$, as a running index, which introduces a new dimension along which consumption and portfolio are considered. In doing so, $R_{e_{2}, t}, R_{f, t}$ and ${ }^{L_{t}}$, become time dependent. In this way, we can see what happens in time and space with the capital. In this case, unlike the static Markowitz portfolio, the accumulation of wealth is not only influenced by the total yield, but also by the 
consumption and thus the saving rate. We start with our results for $\gamma=0.8$. As we can see from figure 1 , given the cyclical returns for the capital interest and the interest rate without risk and starting with the capital near zero, the wealth will be accumulated and then it will move cyclically, as well as the consumption ${ }^{c_{t}}$ and ${ }^{\alpha_{t}}$. However, there is not only a cyclical allocation of assets, presented by the cyclical evolution along the vertical axis, but there is also a tendency in the accumulation of wealth. As the capital is built up to 11500 (horizontal axis) in the time period $t=52$ (vertical axis), a new wealth accumulation cycle begins. So, given the risk aversion parameters and the low rate of reduction, a new cycle of asset accumulation will start from the higher level of wealth. Overall, we will find a tendency and a cyclical component in the accumulation of assets. As a whole, not only is capital accumulated, but it is built faster than for the same mechanism for allocating assets without income from the labor force. The value function for the numerical result illustrated in figure 1 is shown in figure 2 . This shows that welfare evolves cyclically, with the passage of time, starting at $t=0$.

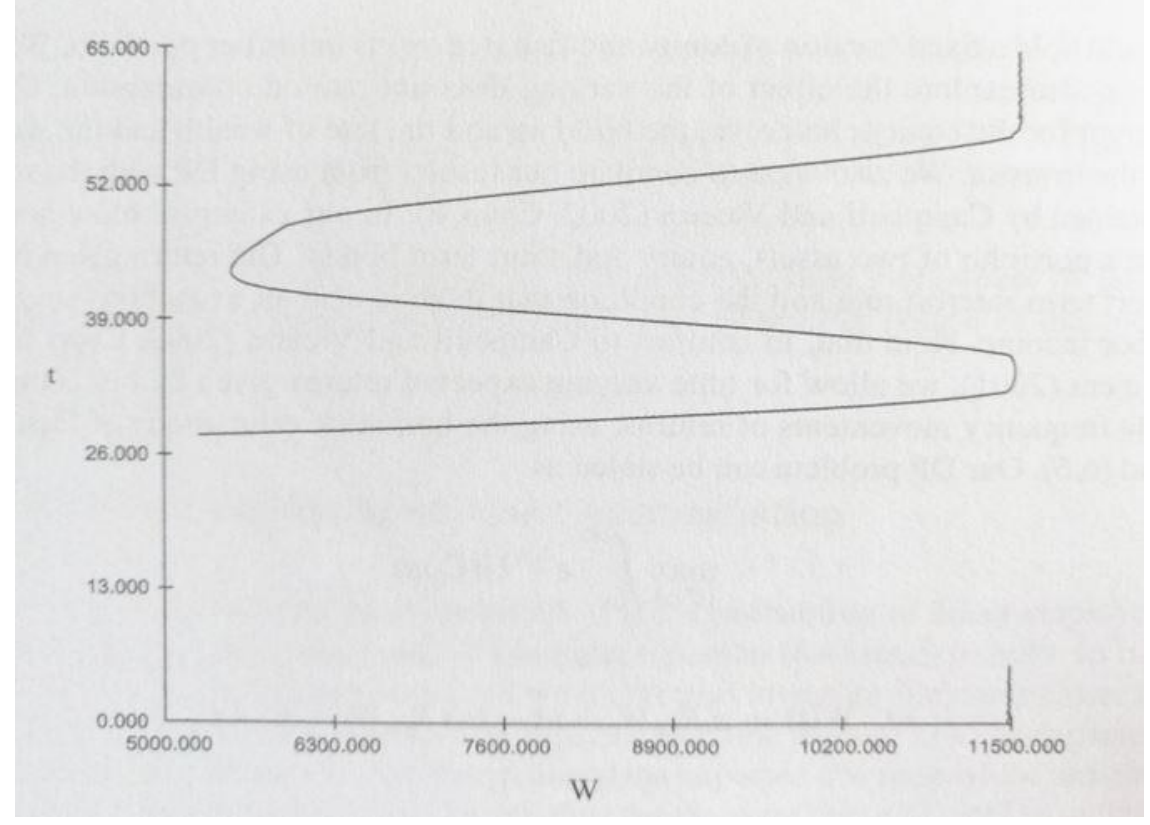

Figure 1. Long variations in asset growth for $\gamma=0,8$ and $\delta=0,03$

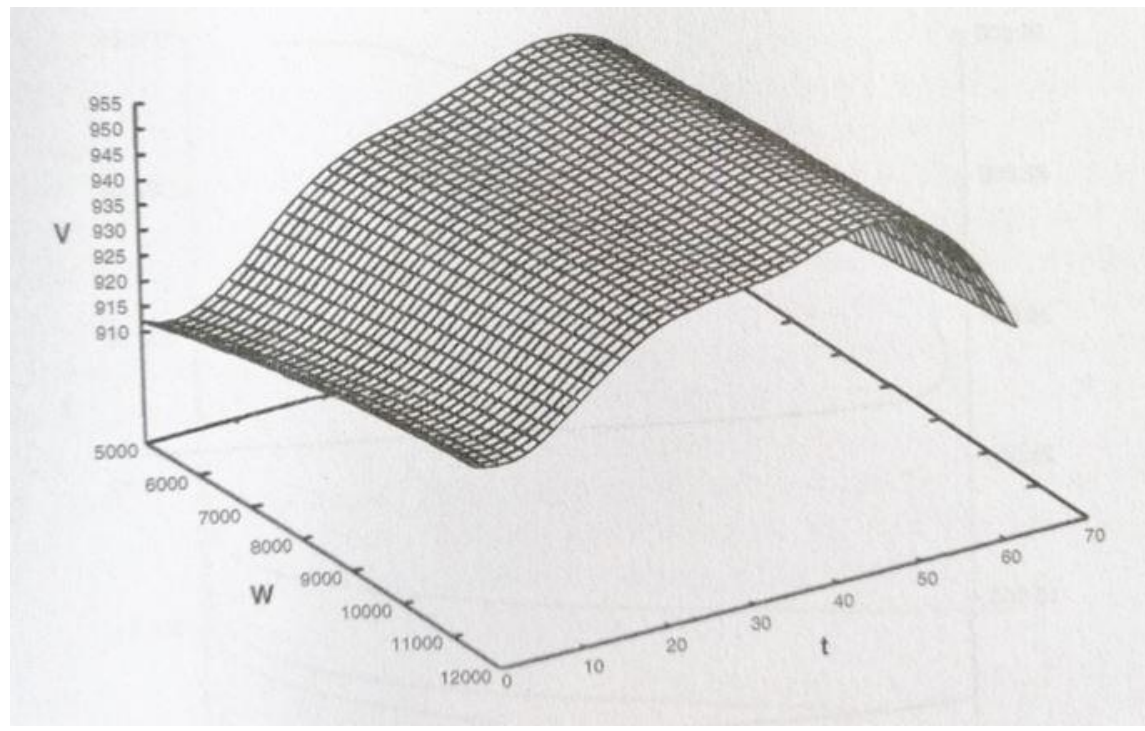

Figure 2. Value function for $\gamma=0,8$ and $\delta=0,03$

The assistance is first small and accumulates in time and by increasing the time, the well-being continues to decrease. In the following calculation we increased the discount rate to $y=0,8$. This is equivalent to still having income from work, but approaching retirement age. However, Figure 3 shows, 
compared to Figure 1, that starting with the high capital, close to 11500 , the wealth will decrease over time. However, after the cycle is completed, this time, as shown in Figure 3, the cycle starts at a lower level, and in the next cycle, the capital continues to decline, as described in Figure 1 . This it is noted that the new cyclical evolution, with $t=0$, the accumulation of wealth starts from a lower level (about 10,500, rather than 11,500 ) and continues to move to the left, which generally means a decrease in capital. Thus, in this case with a high reduction rate, here we also have a cyclical evolution in the accumulation of wealth, but in general, a downward trend of wealth appears. The figure 4 shows the corresponding welfare function for a reduction rate of $\delta=0,5$ therefore $50 \%$. This shows that the welfare is much lower on average over the entire cycle of wealth accumulation. In figure 4 it is also expressed that if the accumulation of wealth takes place (starting at $t=0$ ), then - by the end of the cycle - with the declining wealth, the welfare also decreases. In the next cycle, the variables would move cyclically, but there would be a downward trend in the accumulation of welfare. We will imagine an exercise in which we have no income from work, but only income from assets and, therefore, we assume that the investor is in the retirement period without income from work.

Thus, we study the case where an investor has a short lifespan, with no income from work, but only income from assets. We will use the same risk aversion parameter as before, $v=0,8$ and also the same high rate of investor reduction, $\delta=0,5$. We will try to solve the model through our PD algorithm.

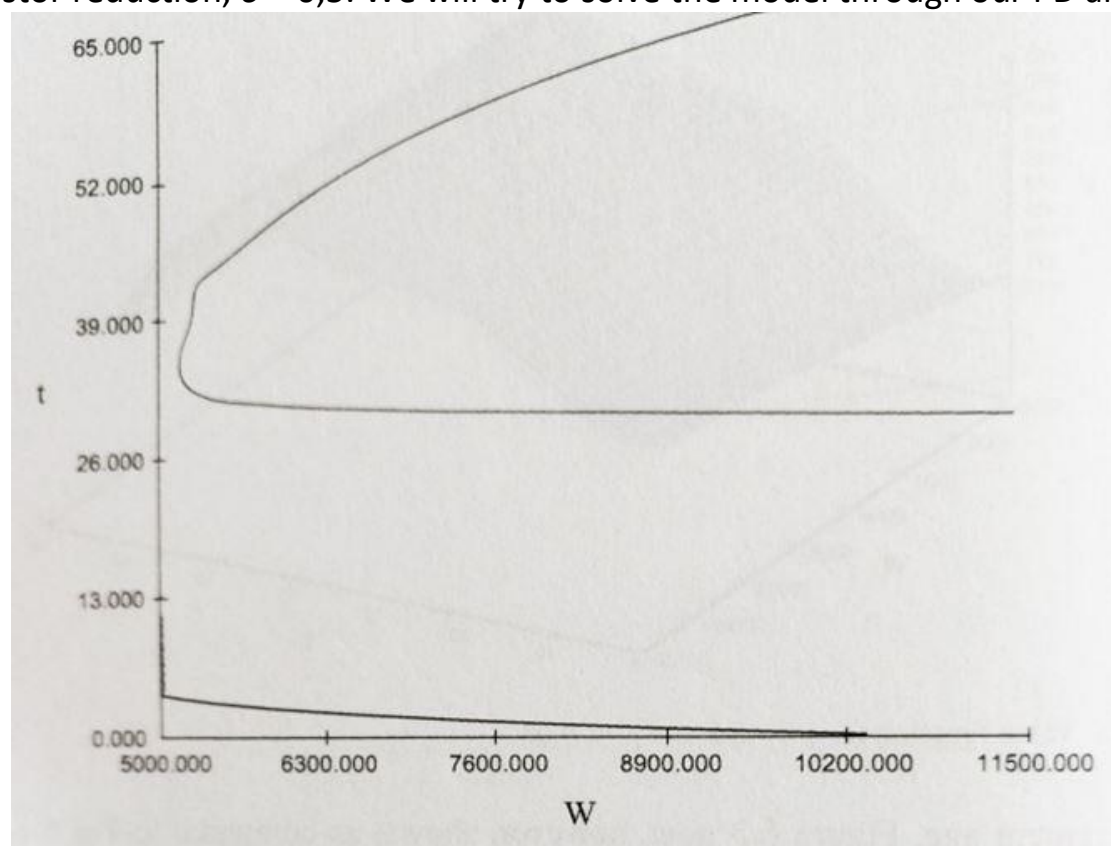

Figure 3. Decline of assets for $\gamma=0,8$ and $\delta=0,05$

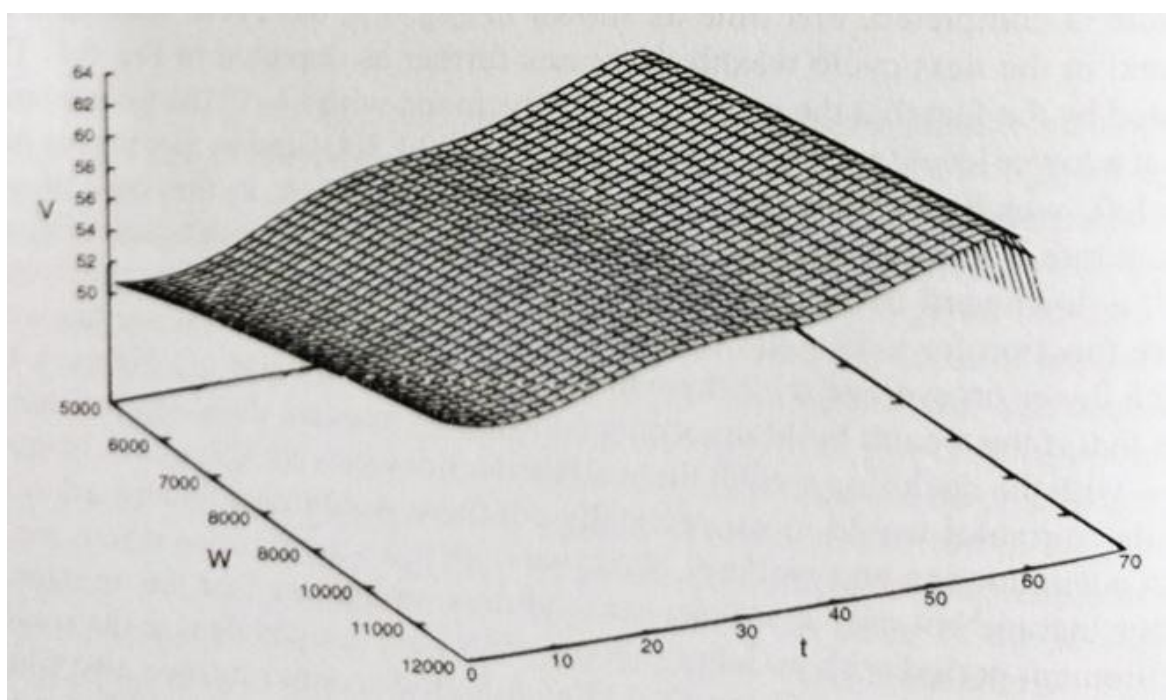

Figure 4. Value function for $\gamma=0,8$ and $\delta=0,05$ 


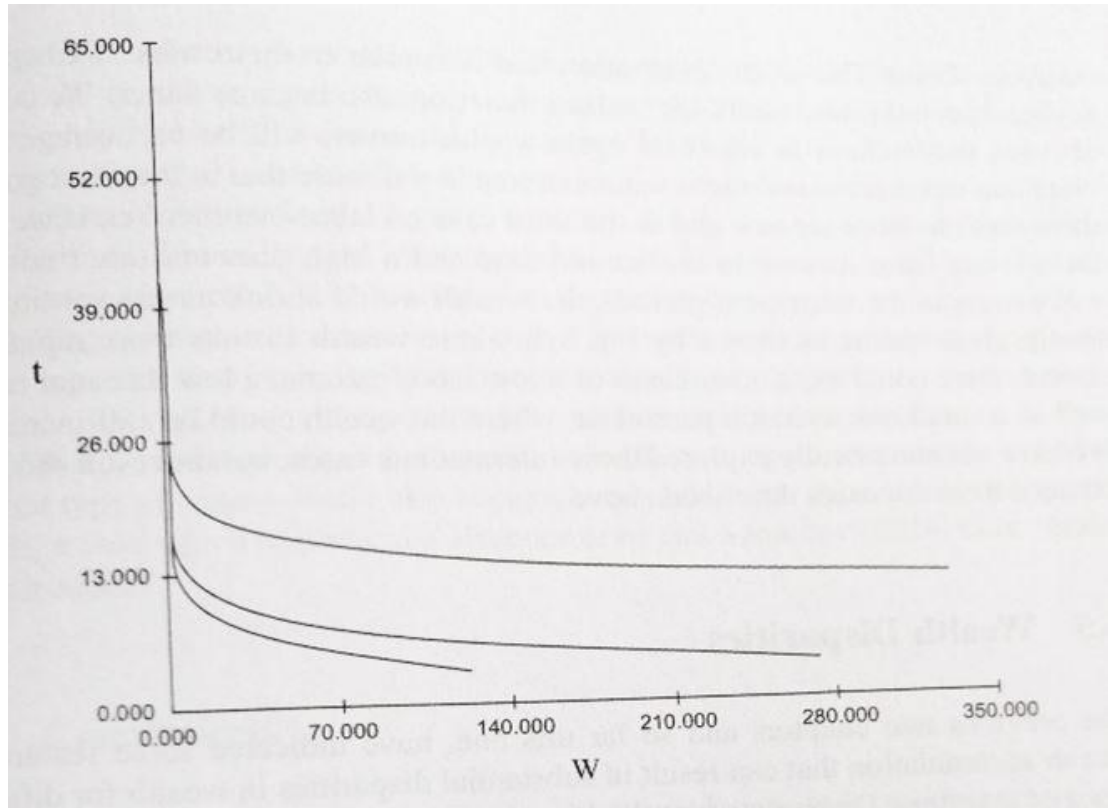

Figure 5. Reduction of wealth without labor income, for $\gamma=0,8$ and $\delta=0,05$

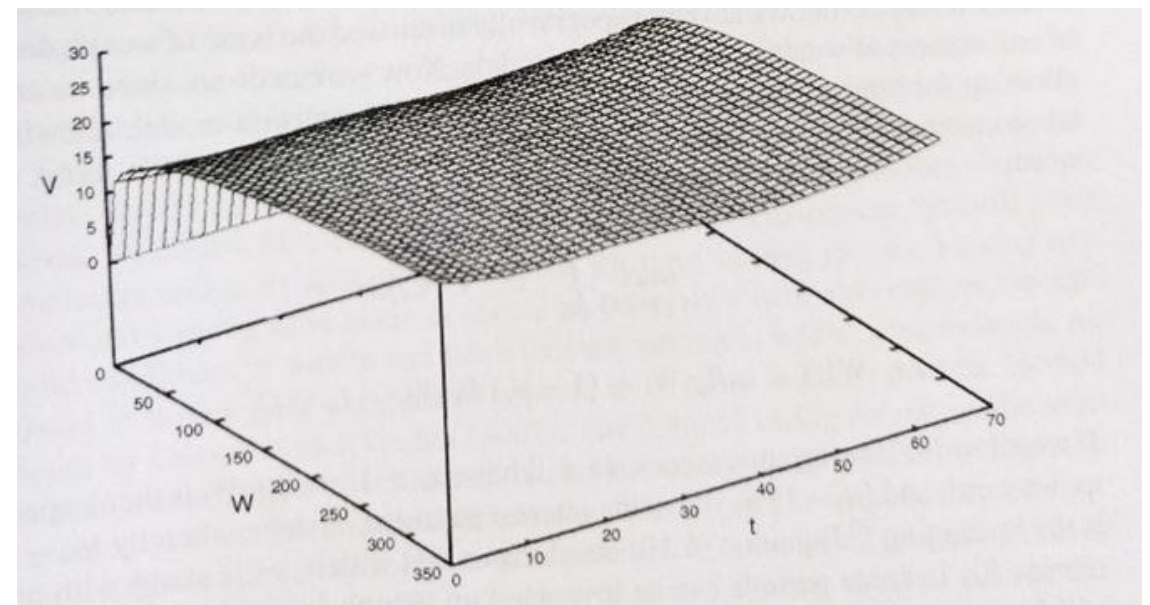

Figure 6. Value function without income from work, for $\gamma=0,8$ and $\delta=0,05$

The figure 5 shows the results for the case without labor income, but a reduction rate of $\delta=0,5$ which means a $50 \%$ reduction rate, which is quite high. In Figure 5 we have presented the trajectories of the capital for different initial conditions of wealth. As we can see, even if we start with very large capital, for example, the initial wealth of about 350,000 or 290,000 , the wealth always dissipates monotonously, as there is no income from work to add income and savings. In fact, as you can see from the charts, all the wealth tends to zero, no matter how big it may have been.

We can see that the welfare, in any cycle of wealth, decreases. The three cases considered might seem extreme, meaning that in the first two cases there was income from work and in the third case, it did not have an income from work. However, if we allow a lower labor income in the second case and a high reduction rate, the wealth would decrease further over time and finally give the results shown in Figure 5 , where the wealth decreases faster. There may be other cases of low income from the labor force, a low rate of reduction, as well as a small risk aversion parameter, where capital may be increasing. Although we have not explored the intermediate cases numerically, the result must be similar to the one from the studies performed.

\subsection{The evolution of earnings among investors}

The ones presented so far have indicated some characteristics of the accumulation of wealth that can lead to substantial disparities of wealth for different types of investors. Capital disparity has become a 
research topic (Piketty (2014), Wolff (2013), Kumhof et al (2015) and Milanovic (2010). Up to this point, we have not specifically addressed the issue of capital difference in the variants of wealth accumulation models. By also allowing income from the workforce, we can extend this study.

Starting from the dynamic decision model, which allows labor and leverage revenues, we can consider a model of the net value, according to the relation:

$$
\begin{aligned}
& \max _{\left\{C_{\mathrm{t}}, \alpha_{\mathrm{t}}>1\right\}} \int_{0}^{\infty} e^{-\delta \mathrm{t}} U\left(C_{t}\right) d t \\
& \dot{W}(t)=\alpha_{t} R_{\theta, t} W_{t}+\left(1-\alpha_{t}\right) R_{f, t} W_{t}+L_{t}-C_{t}
\end{aligned}
$$

If we consider a leverage effect, this means that we will have ${ }^{\alpha_{t}}>1$, the capital $W_{t}$ is expressed as net worth and $\left(\alpha_{t}-1\right) R_{f, t} W_{t}$ is the payment of interest on the debt, by which $\left(\alpha_{t}-1\right) W_{t}$ is the leverage effect. The equation (13) expresses that if $\alpha_{t}>1$, the assets with higher yields $R_{e_{2}, t}$ can be sustained in some periods, although it will have to be paid as a cost of leveraging profits. On the other hand, higher yields can be achieved and wealth can grow faster when extensive exploitation is possible. We can summarize the factors that affect the capital disparities.

We have shown that disparities in wealth accumulation can be due to higher returns, lower risk aversion, longer time horizons and lower reduction rates. Note that besides the income from the assets the non-active income, the income of the labor force could be high and the capital can accumulate faster. All of these will influence the long-term wealth growth. For another group of agents in the financial market, the yield and savings rates can be quite low, so their wealth will grow at a lower rate. In addition, if the market does not allow agents to cope with loan restrictions $\alpha_{t}>1$, as in model (13), and a group of agents with strict loan restrictions $\alpha_{t}<1$, then the first type of agents would accumulate assets faster than the one. second type of agents. We estimated and used low frequency components of labor yields and labor income and used a numerical procedure to evaluate dynamic consumption and asset allocation decisions. We used harmonic estimates to estimate the base frequency components.

We explored asset accumulation decisions and asset allocation decisions for various time returns, variable risk aversion and variable time horizon among investors. At the same time, we also considered the role of the initial conditions of wealth and income from work, adding to the accumulation of wealth. The method used is accurate enough. It turns out that, sometimes, optimal saving decisions, asset allocation, investor welfare, and investor capital fate can be explored quickly and without linearization techniques. One can track the impact of risk aversion variation and time horizon on the dynamics of asset allocation and asset accumulation. We also observe that there are cyclical evolutions in the accumulation of wealth, as well as upward and downward trends in yields evolution, risk aversion, reduction rates, labor income size and saving rate. We have tried to highlight the factors that create disparities in the accumulation of capital. These are not only asset returns, low risk aversion and low reduction rates, but also labor income, savings rates and better leverage.

\section{Conclusions}

The study carried out by the authors is located on the identification of the conditions under which the portfolio decisions are made under the conditions in which the yields are quite variable over time. An important element is the income from work in the form of salary and then of pensions. The models identified and presented are adaptable and can be used to make appropriate portfolio decisions. It follows that there are sufficient assets on the market that come from the income of the labor force and the pensioners.

In this study, we estimated and we used the low frequency components of the return on assets and labor income, and we used a numerical procedure to evaluate dynamic consumption and asset allocation decisions. We use real time series data to estimate the low frequency components of the return on assets and labor income. We use harmonic estimates to estimate the low frequency composers. After we have framed the real time series data, at low frequency components, our numerical procedure is used to solve dynamic consumption and asset decision making. The asset accumulation decisions and asset allocation 
decisions for time varying returns were made under variable risk aversion and variable time horizon among investors. We have determined the role of the initial conditions of wealth and income from work, adding to the accumulation of wealth. The method used is more accurate than other methods. Optimal savings decisions, asset allocation, investor welfare, as well as the fate of investor wealth can be explored without linearization techniques. Through the procedure used, one can track the impact of risk aversion variation and the time horizon between investors on the dynamics of asset allocation and asset accumulation. There are cyclical movements in the accumulation of wealth, as well as upward or downward trends, movements of profitability, risk aversion, reduction rates, the size of the labor income and the saving rate resulting from the study of these factors. We have demonstrated what might be the forces that create disparities in wealth accumulation. These are not only higher returns on assets, reduced risk aversion and reduced rates of reduction, but also higher labor income and higher savings rates.

Greater attention must be paid to the statistical convergence of wage income flows and the return on equity. At the time of retirement, the income from work becomes zero, but there is the possibility of the emergence of assets from pensions, especially in the national system to set up funds for private pensions.

We find that in the asset market we can discuss business cycles, asset returns, as well as labor income. We will find that the variables on the labor market are correlated with the business cycles and, last but not least, with the production.

\section{References}

1. Anghelache, C. (2008). Tratat de statistică teoretică şi economică, Editura Economică, Bucureşti.

2. Bewerunge, P., Rosen, H. (2013). Wages, pensions, and public-private sector compensation differentials for older workers. National Bureau of Economic Research, NBER Working Paper Series, Working Paper No 19454.

3. Campbell, J. V. Viceira, L. M. (2002). Strategic asset allocation: Portofolio choice for long-term investors, Clarendon lectures in economics, Oxford University Press.

4. Chetty, R. (2009). Sufficient Statistics for Welfare Analysis: A Bridge Between Structural and Reduced-Form Methods. Annual Review of Economics, 1 (1), 451-488.

5. Corbore, D., Durlauf, S., Hansen, B. (2006). Econometric Theory and Practice - Frontieres of Analysis and Applied Research, Cambridge University Press, United Kingdom.

6. Hsiao, C.-Y., Semmler, W. (2009). Harmonic Analysis of Long Run Financial Data, Working Paper.

7. Liu, J. (2007). Portofolio selection in stochastic environments. The Review of Financial Studies, 20 (1), 1-39.

8. Markowitz, H. (2010). Portofolio theory: As I still see it, The Annual Review of Financial Economics, 2(1), 1-23.

9. Milanovic, B. (2010). Worlds apart. Measuring international and global inequality, Princeton: Princeton University Press.

10.Newbold, P., Karlson, L. W., Thorne, B. (2010). Statistics for Business and Economics, 7th ed., Pearson Global Edition, Columbia, U.S.

11.Piketty, T. (2014). Capital in the twenty-first century, Boston: Harvard University Press.

12.Van Rooij, M., Kool, C., Prast, H. (2007). Risk-return preferences in the pension domain: Are people able to choose?. Journal of Public Economics, 91, 701-722.

13.Wachter, J. (2002). Portofolio and consumption decisions under mean-reverting returns: An exact solution for complete markets, Journal of Financial and Quantitative Analysis, 37 (1), 63-91.

14.Wolff, E. (2013). The Asset Price Meltdown and the Wealth of the Middle Class, NBER Working Paper No. 18559.

15.Yin, J. (2009). Econometric model of underground Economy Scale Estimation, International Journal of Nonlinear Science, 7 (1), 125-128. 